\title{
Caminhadas interpretativas e conhecimento popular sobre plantas medicinais como forma de Educação Ambiental
}

\author{
Interpretive walks and medicinal plants popular knowledge as an \\ Environmental Education strategy
}

\section{João Luiz de Moraes Hoefel, Nayra de Moraes Gonçalves, Almerinda Antonia Barbosa Fadini}

\begin{abstract}
RESUMO
O processo educativo é um instrumento primordial para entender a complexidade dos problemas ambientais e para propor e executar soluções para estas questões. A interpretação ambiental vem se consolidando como um importante procedimento educacional, possibilitando a transformação de atitudes e posturas, as quais podem contribuir para a formação de uma sociedade mais integrada à natureza. Dentre os métodos disponíveis para a realização de atividades de interpretação ambiental destacamse as caminhadas interpretativas, instrumento pedagógico que visa possibilitar ao indivíduo relacionar-se com o meio, e serem realizadas em momentos de lazer. Desta forma o presente trabalho, que integra o Projeto de Pesquisa FAPESP 2008/10631-0 - Pharmácia do Mato - Transformações Socioambientais e Uso de Plantas Medicinais, tem como objetivo apresentar caminhadas interpretativas com foco no conhecimento e uso popular de plantas medicinais que vêm sendo realizadas na Área de Proteção Ambiental Fernão Dias/MG (APA Fernão Dias). Esta APA apresenta uma expressiva população rural e significativos remanescentes de Mata Atlântica, utilizados como fontes de plantas para uso medicinal, mas nas últimas décadas vem passando por um intenso processo de alterações socioambientais. A caminhada interpretativa, que utiliza a técnica guiada, está sendo desenvolvida em Camanducaia/MG e visa demonstrar a utilidade das plantas na medicina popular e sensibilizar os participantes quanto à importância da conservação ambiental. A caminhada foi testada com um grupo inicial de moradores, alunos de pós-graduação e turistas que avaliaram positivamente seus diferentes aspectos e no momento encontra-se em uma fase mais ampla de divulgação. Observa-se a partir da prática que a utilização de plantas medicinais está intimamente relacionada à identidade cultural da população local e que a manutenção deste conhecimento é essencial, já que pode orientar o manejo e possibilitar a conservação das áreas naturais, bem como compor propostas de educação ambiental que auxiliem na sustentabilidade socioambiental da área.
\end{abstract}

PALAVRAS-CHAVE: Educação Ambiental; Caminhadas Interpretativas; Plantas Medicinais. 
Caminhadas interpretativas e conhecimento popular sobre plantas medicinais como forma de Educação Ambiental.

\begin{abstract}
The educational process is an essential tool to understand the complexity of environmental problems and to propose and implement solutions to these issues. The environmental interpretation has been used as an important educational procedure, enabling the transformation of attitudes and values, which can contribute to the formation of a society more integrated with nature. Among the methods available to carry out activities of environmental interpretation we can highlight the interpretive walks, an educational tool that aims to enable the individual to relate himself with the environment and that can be accomplished in a moment of leisure. Thus the present work, part of the Research Project FAPESP 2008/10631-0 - Pharmacia do Mato Social and Environmental Transformations and Use of Medicinal Plants, aims to present interpretive walks with a focus on the popular knowledge and use of medicinal plants that has been realized in the Fernão Dias Environmental Protected Area/MG (Fernão Dias EPA). This EPA has both a significant rural population and remnants of Atlantic Forest used as sources of plants for medical use, but in recent decades has undergone an intense process of socioenvironmental changes. The interpretive walk, which uses a guided technique, is being developed in Camanducaia/MG and aims to demonstrate the usefulness of plants in popular medicine and educate participants on the importance of environmental conservation. The walk was tested with a group of residents, graduate students and tourists who positively evaluated its different aspects and is currently in a stage of wider advertising. It is observed from the practice that the use of medicinal plants is closely related to the cultural identity of the local population and the maintenance of this knowledge is essential because it can contribute both to the management and enable the preservation of natural areas, as well as support environmental education proposals that assist socioenvironmental sustainability.
\end{abstract}

KEYWORDS: Environmental Education; Interpretive Walks; Medicinal Plants.

\title{
Ecoturismo, Educação e Interpretação Ambiental
}

Apesar das amplas discussões sobre as questões ambientais serem recentes, as civilizações humanas vêm historicamente transformando o ambiente em que vivem de acordo com suas necessidades e desejos. Estas alterações possibilitam prosperidade e avanço para algumas sociedades, mas ao mesmo tempo geram sérias desigualdades e problemas socioambientais o que têm estimulado estudos que aprofundem o conhecimento sobre as relações ser humano/natureza, na busca por soluções para diversos aspectos já identificados da problemática do meio ambiente (GUHA, 2000).

A crise ambiental tem determinado um questionamento dos valores da sociedade contemporânea e aponta para a necessidade de uma profunda reorientação nos modos socialmente construídos de conhecer e se relacionar com a natureza. Esta situação tem estimulado a busca e implantação de diferentes estratégias que auxiliem na resolução dos problemas já detectados, e dentre elas, podemos destacar as ativi- 
dades de Educação Ambiental (EA).

A Educação Ambiental num processo interdisciplinar tem procurado apontar caminhos que possibilitem uma revisão e transformação dos valores que regem a ação humana e uma maior compreensão das dinâmicas históricas e socioambientais. Dentre as medidas que vêm sendo adotadas para alcançar esta proposição, destaca-se a interpretação e releitura dos processos históricos e sua incorporação em propostas de ação.

Através de estratégias de Educação Ambiental é possível identificar e reconhecer processos sociais e naturais a partir dos lugares onde estes são produzidos. Isto exige a interpretação e valorização da história do lugar, bem como a caracterização das alterações sócio-culturais e ambientais no decorrer do tempo.

Na visão de Novo (2002), um dos grandes erros da tecnociência tem sido o estabelecimento de regras e projetos gerais que ignoram, na maioria dos casos, as peculiaridades específicas dos contextos geográficos e culturais, contribuindo para a devastação da diversidade ecológica e cultural. A fragilidade e vulnerabilidade de cada ecossistema só podem ser definidas corretamente se forem consideradas suas especificidades ecológicas, seus desenvolvimentos históricos e suas características culturais.

Dentre os conceitos existentes para o termo Educação Ambiental, o Tratado de Educação Ambiental para Sociedades Sustentáveis e Responsabilidade Global (1992) considera que a mesma:

\footnotetext{
É um processo de aprendizagem permanente, baseado no respeito a todas as formas de vida. Tal educação afirma valores e ações que contribuem para a transformação humana e social e para a preservação ecológica. Ela estimula a formação de sociedades socialmente justas e ecologicamente equilibradas, que conservam entre si relação de interdependência e diversidade. Isso requer responsabilidade individual e coletiva a nível local, nacional e planetário. (...) A Educação Ambiental deve gerar, com urgência, mudanças na qualidade de vida e maior consciência de conduta pessoal, assim como harmonia entre os seres humanos e destes com outras formas de vida (VIEZZER; OVALLES, 1994, p. 29).
}

Considera-se que a Educação Ambiental é um processo de ensino aprendizagem para o exercício da cidadania, da responsabilidade social e política, cabendo a ela a construção de novos valores e novas relações sociais dos seres humanos com a natureza, e da melhoria da qualidade de vida para todos os seres vivos (PHILIPPI JR; PELICIONI, 2002). A Educação Ambiental para Sauvé (2005) representa a busca por uma educação que esteja pautada na conservação e preservação ambiental através da construção de novos valores, atitudes e percepções, bem como na visão ampla e 
Caminhadas interpretativas e conhecimento popular sobre plantas medicinais como forma de Educação Ambiental.

sistêmica do meio ambiente. Para Luzzi (2005) a solução dos problemas ambientais não se encontra apenas na gestão dos recursos naturais e na incorporação das externalidades ambientais, mas também através da mudança de pensamento e sentimento em relação à natureza. O autor enfatiza que a EA "marca uma nova função social da educação, é responsável pela transformação da educação como um todo, em busca de uma sociedade sustentável' (p.399).

O processo educativo vem consolidando-se como uma ferramenta para entender a complexidade dos problemas ambientais e propor e executar soluções para estas questões. Por problemas ambientais entende-se não apenas os conflitos gerados entre pessoa(s) e natureza, mas também aqueles gerados entre pessoa(s) e pessoa (s), numa perspectiva de que não é a natureza que está em crise, mas sim as bases nas quais a maior parte das sociedades atuais se mantém (LEFF, 2003).

A interpretação é um importante instrumento educacional, já que através da mesma é possível promover a transformação de atitudes e posturas que contribuam para a formação de uma sociedade mais integrada à natureza. Para Tilden (1957 apud PEREIRA, 2004) a interpretação é uma atividade educacional que tem por objetivo revelar significados e relações presentes no ambiente que possibilitam uma experiência profunda.

Pagani (1996, p.154) caracteriza a interpretação ambiental como

(...) uma técnica didática, flexível e moldável às mais diversas situações, que busca esclarecer os fenômenos da natureza para determinado público alvo, em linguagem adequada e acessível, utilizando os mais variados meios auxiliares para tal.

Segundo Pereira (2004) a interpretação pode ser entendida como um processo de comunicação que explica ao público o significado do local visitado, com o intuito de proporcionar uma visita agradável, melhor entendimento da cultura ou meio ambiente e sensibilização quanto à conservação dos mesmos.

Neste sentido, a interpretação pode ser diretamente relacionada ao ecoturismo, visto que, de acordo com o documento Diretrizes para uma Política Nacional de Ecoturismo, o mesmo deve abranger o conhecimento da natureza, a experiência educacional interpretativa, a valorização das culturas tradicionais locais e a promoção do desenvolvimento sustentável, definindo a referida atividade como

o segmento da atividade turística que utiliza, de forma sustentável, o patrimônio natural e cultural, incentiva sua conservação e busca a formação de uma consciência ambientalista através da interpretação do ambiente, promovendo o bem estar das populações envolvidas (BRASIL, 1994, p.19).

Segundo o Ministério do Turismo (BRASIL, 2008) o ecoturismo possui uma pro- 
posta de contemplação e conservação da natureza, possibilitando interação e experimentação da mesma de forma sustentável.

Devido à existência de muitas terminologias para definir uma atividade semeIhante, não há um consenso geral acerca do conceito da mesma, contudo, entre as definições para o termo ecoturismo estão sempre presentes as seguintes características: conservação ambiental, Educação Ambiental e beneficio às comunidades locais (FACO; NEIMAN, 2010; FENNELL, 2002; BRASIL, 2008). Entretanto há conflitos práticos e conceituais acerca do mesmo, já que corresponde a uma atividade econômica.

Para Neiman (2008) o ecoturismo no Brasil é uma atividade controversa, pois enquanto os especialistas o entendem como a melhor alternativa para conciliar conservação, Educação Ambiental e benefícios à comunidade, ainda é uma atividade que funciona "à mercê da lógica do mercado". Neiman e Rabinovici (2008) consideram que a possível escassez dos bens naturais despertou nos indivíduos a urgência em conhecer determinados atrativos antes que os mesmos se esgotem, o que os transformou em produtos e atraiu mercados.

É importante destacar que o ecoturismo, como qualquer atividade, pode produzir impactos positivos ou negativos, contudo esses efeitos são potenciais, isto é, dependem do modo como o mesmo é planejado, implantado e monitorado. Se desenvolvido de forma adequada, pode ser uma alternativa sustentável de, ao mesmo tempo, explorar e conservar os recursos naturais, oferecendo experiências autênticas, proporcionando uma vivência com novas culturas e ambientes.

Sanders (2004) acredita que os defensores do ecoturismo como atividade econômica frequentemente exageram seus benefícios e ignoram o fato de que os recursos utilizados na atividade ecoturística poderiam ser utilizados para produzir outros bens e serviços e também gerariam renda e oportunidades. Por outro lado, o autor salienta que em geral os críticos de ecoturismo exageram seus impactos potenciais adversos e ignoram o fato de que, na ausência do mesmo, provavelmente alguma outra forma de atividade econômica ocorreria naquela área, o que também poderia gerar impactos danosos.

Por outro lado alguns autores (GEERDINK; NEIMAN, 2010; DIAS, 2003) apontam que o ecoturismo pode ser um instrumento para a Educação Ambiental, já que sua prática favorece o contato com a natureza e permite a reflexão. "A experiência de turismo (...) em meio ao mundo natural ajuda a refletir sobre os comportamentos de cada indivíduo e a desenvolver um pensamento crítico em relação à sociedade na qual está inserido (...)" (GEERDINK; NEIMAN, 2010, p. 68).

Através da interpretação dos aspectos naturais e culturais de determinada localidade, busca-se despertar os recursos sensoriais e a criticidade do visitante, através de um processo que envolve a revalorização dos lugares e a compreensão da linguagem da natureza (LIMA et al., 2003).

Dentre os métodos disponíveis para a realização de atividades de interpretação 
Caminhadas interpretativas e conhecimento popular sobre plantas medicinais como forma de Educação Ambiental.

ambiental destacam-se as caminhadas interpretativas, instrumento pedagógico que pode possibilitar ao indivíduo relacionar-se com o meio, e ser realizada em um momento de lazer.

Guimarães (2008) salienta que as trilhas interpretativas são atividades "formativas e informativas que provocam novos processos de adaptação e assimilação relativos ao desenvolvimento de experiências e conhecimentos relacionados ao meio ambiente (...)" (GUIMARÃES, 2008, p. 67).

As trilhas de interpretação ambiental compreendem um percurso geralmente feito a pé, por caminho já existente e definido previamente, em local que favoreça a observação de aspectos do ambiente natural ou antrópico (SAUL et al., 2002). Esta técnica tem como objetivo principal estimular nos participantes a percepção e gerar a integração entre o homem e a natureza. Vasconcellos (1997) aponta que a utilização de técnicas interpretativas contribui para a compreensão de fatos que estão além das aparências, como leis naturais, interações, história ou mesmo aspectos visíveis que não são comumente percebidos. E, segundo Neiman e Rabinovici (2008) o contato com a natureza oferece a oportunidade de vivenciar emoções e resgatar sentimentos que foram esquecidos durante o processo de desenvolvimento da sociedade.

\section{Uso de plantas medicinais}

A deterioração dos ecossistemas, a heterogeneidade dos problemas de saúde, o crescimento desordenado das cidades são exemplos de situações em que a crescente complexidade social demanda novas formas de enfrentamento científico e tecnológico, para propiciar-nos uma melhor qualidade de vida (BUTTEL, 2000).

A degradação ambiental, a contaminação de trabalhadores e consumidores, as doenças ocupacionais e mortalidade - frequentemente invisíveis no conjunto das estatísticas de saúde - são coletivamente absorvidas pela sociedade e pelos sistemas públicos de saúde e muitas vezes exigem que as pessoas recorram a soluções e práticas tradicionais (BARBOSA; HOEFFEL, 2008).

Neste contexto o conhecimento sobre plantas medicinais simboliza muitas vezes o único recurso terapêutico de muitas comunidades e grupos étnicos. $O$ uso de plantas no tratamento e na cura de enfermidades é tão antigo quanto a espécie humana (LEWINGTON, 1990) e, ainda hoje, nas regiões mais pobres do país e até mesmo nas grandes cidades brasileiras, plantas medicinais são comercializadas em feiras livres, mercados populares e cultivadas em quintais residenciais (MACIEL et al., 2002).

Entretanto, o aumento no uso de plantas medicinais tem segundo diversos autores (MARIOT; REIS; DI STASI, 2000; AZEVEDO; SILVA, 2002; CUNHA, 2003), aumentado a pressão ecológica exercida sobre esses recursos naturais. Assim, tanto o valor econômico, o extrativismo predatório, quanto o comércio local, além da degradação ambiental dos ambientes naturais colocam em risco muitas espécies medicinais nativas (MARIOT; REIS; DI STASI, 2000). Por outro lado, a desagregação dos sistemas de vida tradicionais, que acompanha a degradação ambiental, e a inserção de 
novos elementos culturais ameaçam um acervo de conhecimentos empíricos e um patrimônio genético de valor inestimável (RODRIGUES; GUEDES, 2006).

As culturas tradicionais elaboraram ideias sofisticadas de saúde e bem-estar e para muitas a saúde não é a mera ausência de doença e sim um estado de equilíbrio espiritual, de convivência comunitária e ecológica, com a inclusão em sistemas de cura tanto de remédios para cura física, quanto para a melhoria e fortalecimento do bem -estar. Verifica-se, portanto, que as práticas relacionadas ao uso popular de plantas medicinais são o que muitas comunidades têm como alternativa viável para o tratamento de doenças ou manutenção da saúde. Porém, sua continuidade pode ser ameaçada pela interferência de fatores externos à dinâmica social do grupo.

Neste contexto insere-se a área de estudo do presente trabalho, a Área de Proteção Ambiental Fernão Dias/MG (APA Fernão Dias), que apresenta uma expressiva população rural e significativos remanescentes de Mata Atlântica, utilizados como fontes de plantas para uso medicinal, mas que nas últimas décadas vem passando por um intenso processo de alterações socioambientais.

Hoeffel et al. (2011) observam que a utilização de plantas medicinais está intimamente relacionada à identidade cultural da população local e que a manutenção deste conhecimento é essencial, já que pode orientar o manejo e possibilitar a conservação das áreas naturais, bem como a sua utilização em propostas de Educação Ambiental que auxiliem na sustentabilidade socioambiental da área de estudo.

Desta forma, o presente trabalho, que integra o Projeto de Pesquisa FAPESP 2008/10631-0 - Pharmácia do Mato - Transformações Socioambientais e Uso de Plantas Medicinais, tem como objetivo apresentar caminhadas interpretativas com foco no conhecimento e uso popular de plantas medicinais que vem sendo realizadas na APA Fernão Dias.

\section{Caracterização da área de estudo}

Segundo o Sistema Nacional de Unidades de Conservação - SNUC - a Área de Proteção Ambiental corresponde a uma Unidade de Conservação pertencente à categoria de Uso Sustentável e é definida como

(...) uma área em geral extensa, com um certo grau de ocupação humana dotada de atributos abióticos, bióticos, estéticos ou culturais especialmente importantes para a qualidade de vida e o bem-estar das populações humanas e tem como objetivo básico proteger a diversidade biológica, disciplinar o processo de ocupação e assegurar a sustentabilidade do uso dos recursos naturais (BRASIL, 2000: 17).

A APA Fernão Dias (Figura 1) foi criada a partir do Decreto Estadual $n^{\circ} 38.925$ de Julho de 1997 com o objetivo principal de proteger e preservar as formações flo- 
Caminhadas interpretativas e conhecimento popular sobre plantas medicinais como forma de Educação Ambiental.

restais remanescentes da Mata Atlântica e a fauna silvestre, visando à melhoria da qualidade ambiental e de vida da população (MINAS GERAIS, 1997).

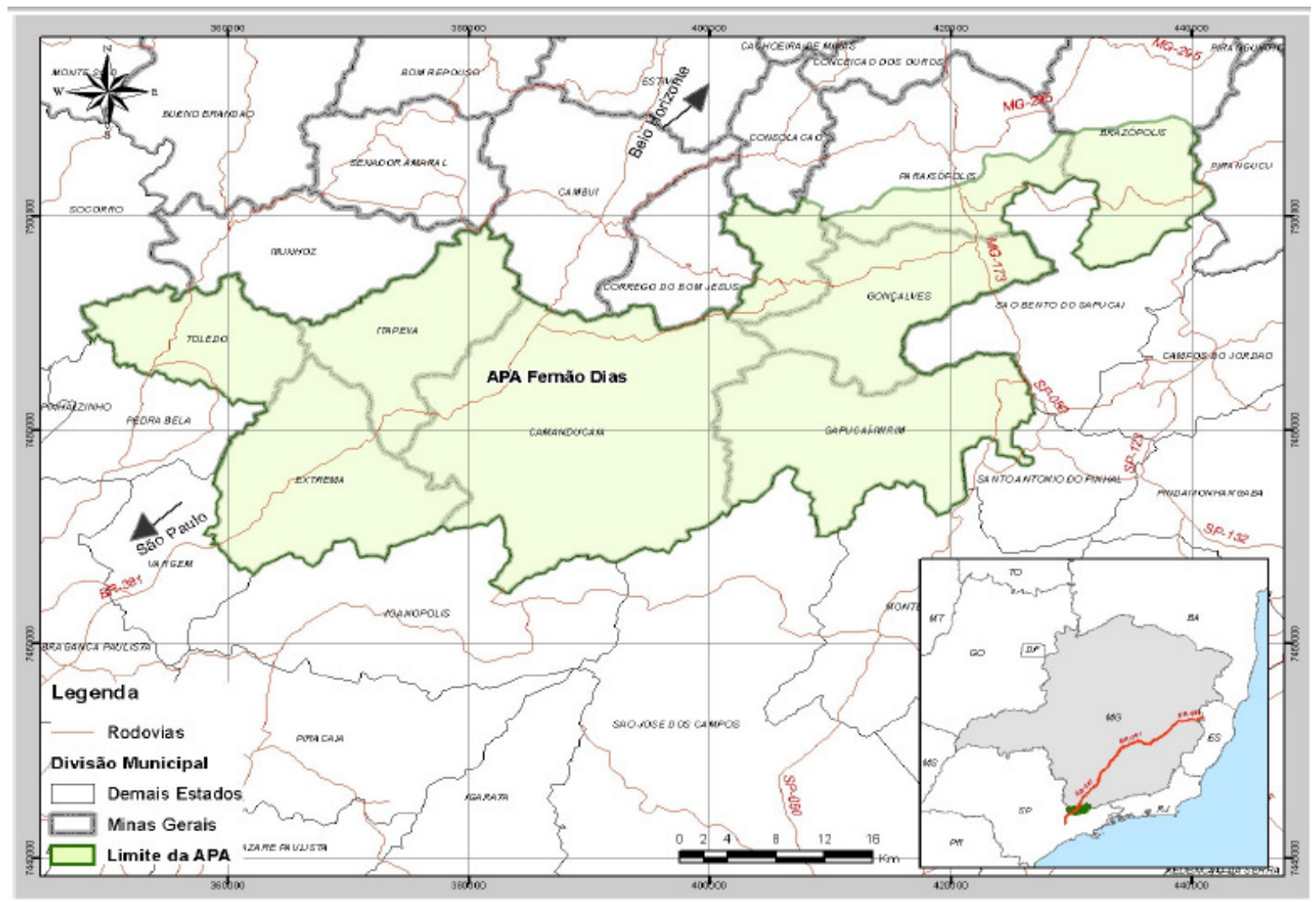

Figura 1: Mapa de localização da APA Fernão Dias (OLIVEIRA, 2007).

A APA Fernão Dias é considerada uma área prioritária para a conservação da flora de Minas Gerais, com importância biológica muito alta (áreas de riqueza de espécies endêmicas, ameaçadas ou raras, remanescentes significativos, altamente ameaçados ou com alto grau de conservação) (DRUMMOND, 2005). Ainda segundo a autora, as pressões antrópicas mais importantes identificadas para a flora foram a monocultura, a expansão urbana e as atividades agropecuárias.

A região ainda possui remanescentes significativos de Mata Atlântica (Figura 2), que, associados à sua beleza natural, faz com que ela se torne alvo de empreendimentos imobiliários os mais diversos, consolidando um processo crescente de ocupação do solo e uso turístico desordenado (HOEFFEL et al., 2004; 2005).

O fácil acesso à área contribui para acelerar o processo de industrialização e o consequente crescimento urbano em alguns municípios, gerando impactos diversos, que são acentuados quando considerada a importância dos fragmentos florestais, jus- 
Hoefel, J.L.M.; Gonçalves, N.M.; Fadini, A.A.B.

tificada, entre outros motivos, pela diversidade e endemismo de espécies tanto de flora como de fauna (HOEFFEL; GONÇALVES; FADINI, 2010).

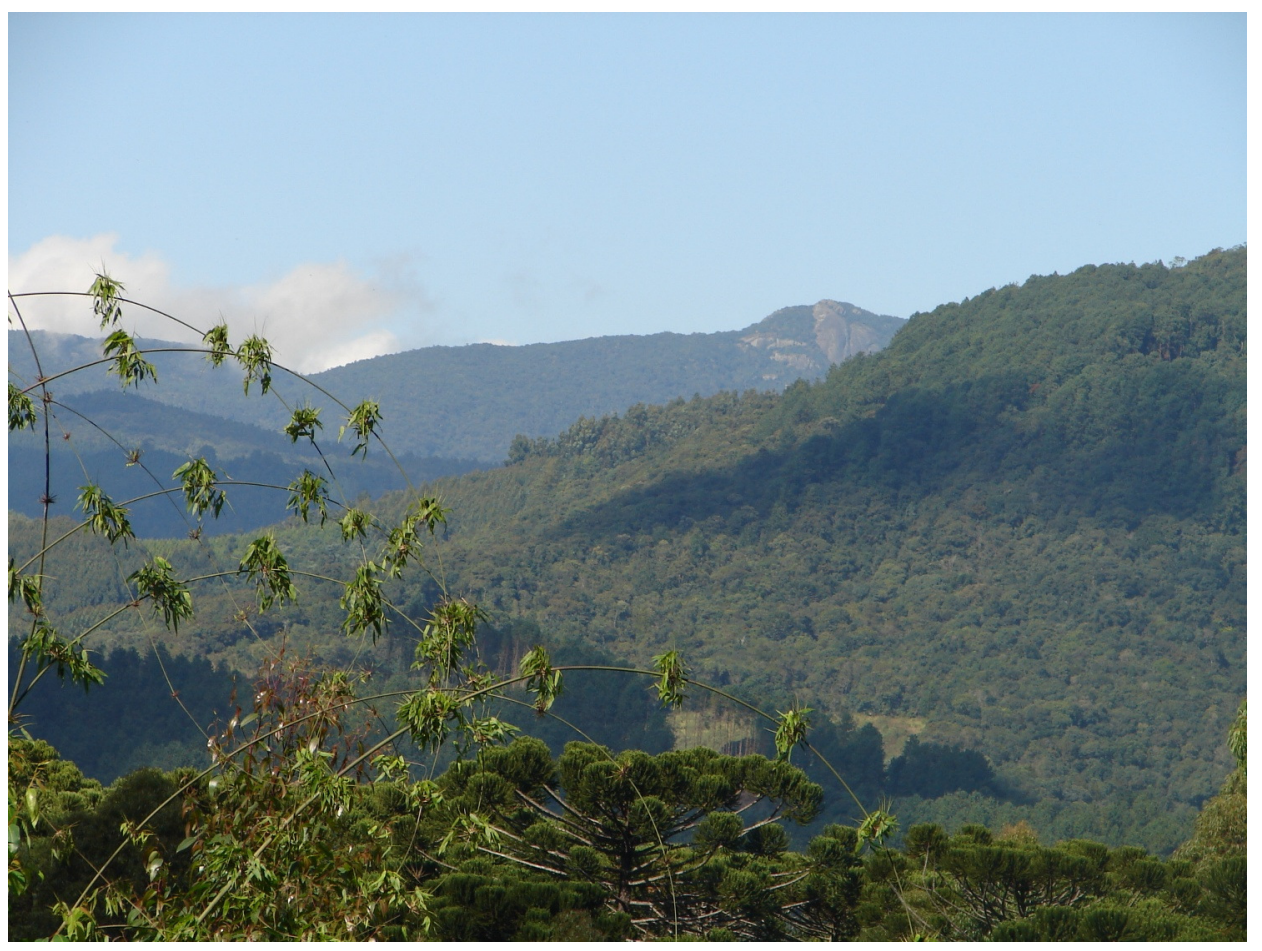

Figura. 2: Fragmentos de Mata Atlântica e Reflorestamentos, Camanducaia, MG Foto: João Luiz Hoefel, maio/2011.

A crescente urbanização pela qual esta região vem passando determinou profundas transformações socioambientais, que resultaram na alteração do modo de vida da população local (HOEFFEL et al., 2008). Segundo relatos dos entrevistados, os jovens não possuem interesse em aprender as práticas medicinais, pois possuem acesso facilitado a hospitais e medicamentos industrializados, além da maior praticidade oferecida pelos "remédios de farmácia".

A facilidade de acesso a tratamentos médicos e o deslocamento cada vez maior das pessoas para as regiões urbanas são as principais causas da significativa redução do uso de plantas medicinais e a consequente desvalorização deste conhecimento tradicional. Considera-se, em função do quadro de alterações socioambientais observadas na área de estudo (HOEFFEL; FADINI; SEIXAS, 2010), que são necessárias estratégias para o desenvolvimento local sustentável que auxiliem na conservação dos recursos naturais e na valorização deste importante elemento cultural.

Acerca do uso de plantas medicinais, Begossi, Hanazaki e Tamashiro (2002) afirmam haver a possibilidade de relacionar conhecimento local, Educação Ambiental 
Caminhadas interpretativas e conhecimento popular sobre plantas medicinais como forma de Educação Ambiental.

e atividade econômica alternativa, resultando em uma ferramenta para o desenvolvimento local sustentável.

Neste sentido, estão sendo desenvolvidas atividades de Educação Ambiental, centradas na realização de caminhadas interpretativas, que têm como foco o conhecimento e uso de plantas medicinais regionais, já que esta atividade como instrumento pedagógico pode possibilitar ao indivíduo relacionar-se com o meio e ser realizada em um momento de lazer.

A realidade socioambiental desta APA demonstra que esta apresenta vulnerabilidades que geram riscos diversos, como a redução e/ou extinção de espécies, processos erosivos, assoreamentos, desmatamentos, vários tipos de poluição, destacando-se a hídrica, entre outros, os quais estão diretamente relacionados aos usos agrícolas, à expansão urbana e industrial, ao uso turístico e caça indiscriminada.

Por este motivo, é que uma gestão responsável associada a práticas de Educação Ambiental pode-se mostrar eficaz, uma vez que permite despertar e fortalecer a consciência da população para diversas questões ambientais e estimular a busca, individual e coletiva, por soluções coerentes com as características socioambientais destas unidades de conservação.

\section{Caminhada "Remédios do Mato", o foco em plantas medicinais}

A caminhada interpretativa está sendo desenvolvida em Camanducaia/MG, município núcleo de estudo, e visa demonstrar a utilidade das plantas na medicina popular e sensibilizar os participantes quanto à importância da conservação ambiental.

A técnica escolhida foi a caminhada guiada, ou seja, com a presença de um intérprete que acompanha, conduz e direciona os visitantes de acordo com os seus objetivos. Lima et al. (2003) destacam que este tipo de caminhada proporciona a interação entre público e intérprete, além de haver a possibilidade de incorporar como guias os membros da comunidade local, representando assim uma nova forma de atividade econômica associada à sustentabilidade socioambiental.

A caminhada é realizada em uma propriedade rural denominada de Fazenda Mandaçaia, localizada no Bairro Ponte Nova, que possui um expressivo remanescente florestal de Mata Atlântica de Altitude, e seu proprietário, apesar de não ser nativo do município, é um profundo conhecedor da flora local. O trajeto utilizado abrange triIhas em áreas antropizadas e em áreas de floresta nativa (Figuras 3 e 4) em estágio secundário de regeneração de grande beleza cênica, que abrigam uma variedade de plantas medicinais, perfazendo um percurso de aproximadamente $5 \mathrm{~km}$.

Em levantamento realizado no decorrer deste projeto verificou-se que em Camanducaia grande parte das plantas medicinais utilizadas encontra-se dispersa no mato em áreas florestadas e identificou-se o uso de 138 espécies neste município, das quais 76 são nativas, 56 são exóticas e 06 não puderam ser identificadas (HOEFFEL et al., 2011) (Figuras 5, 6, 7, 8, 9, 10). 
Hoefel, J.L.M.; Gonçalves, N.M.; Fadini, A.A.B.

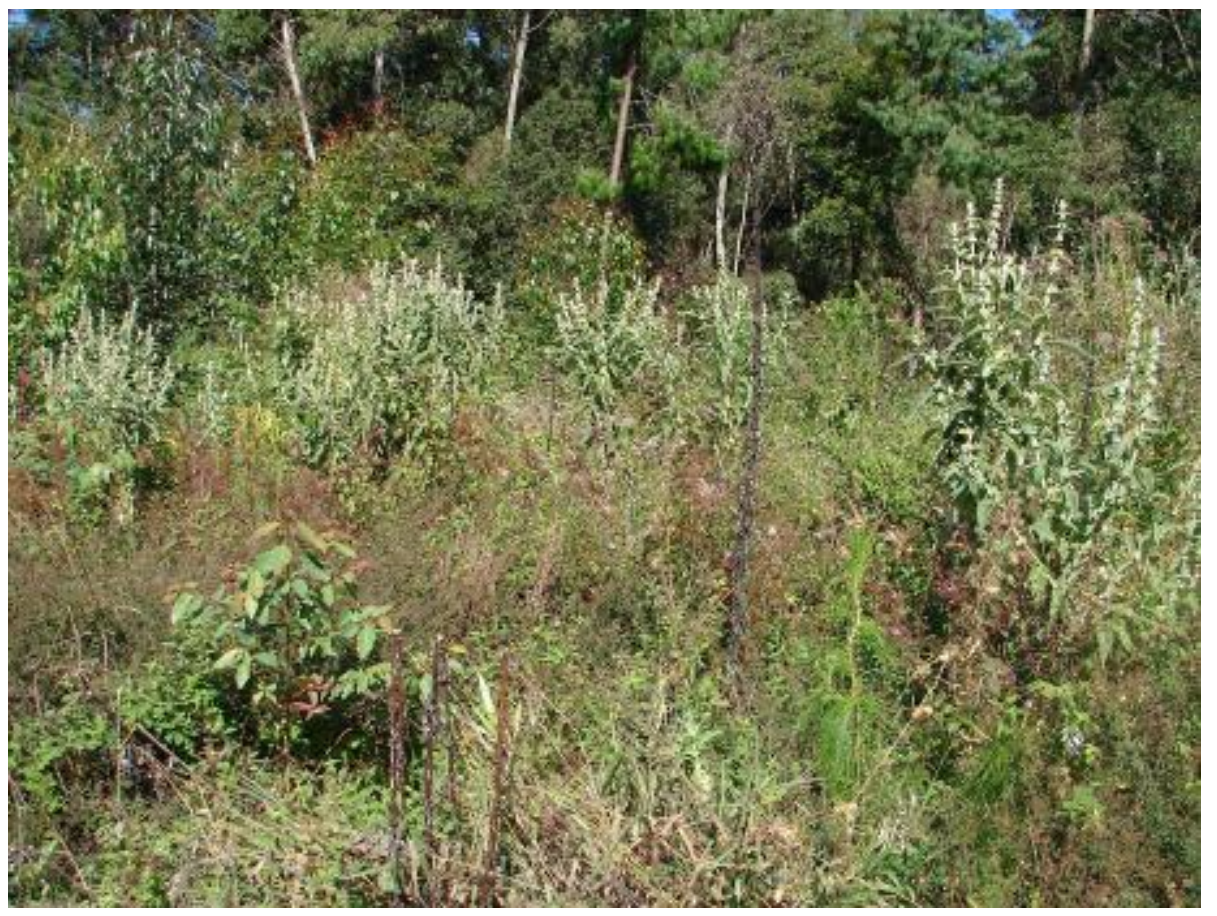

Figura 3: Área antropizada na Fazenda Mandaçaia, Camanducaia, MG Foto: Almerinda Fadini, maio/2011.

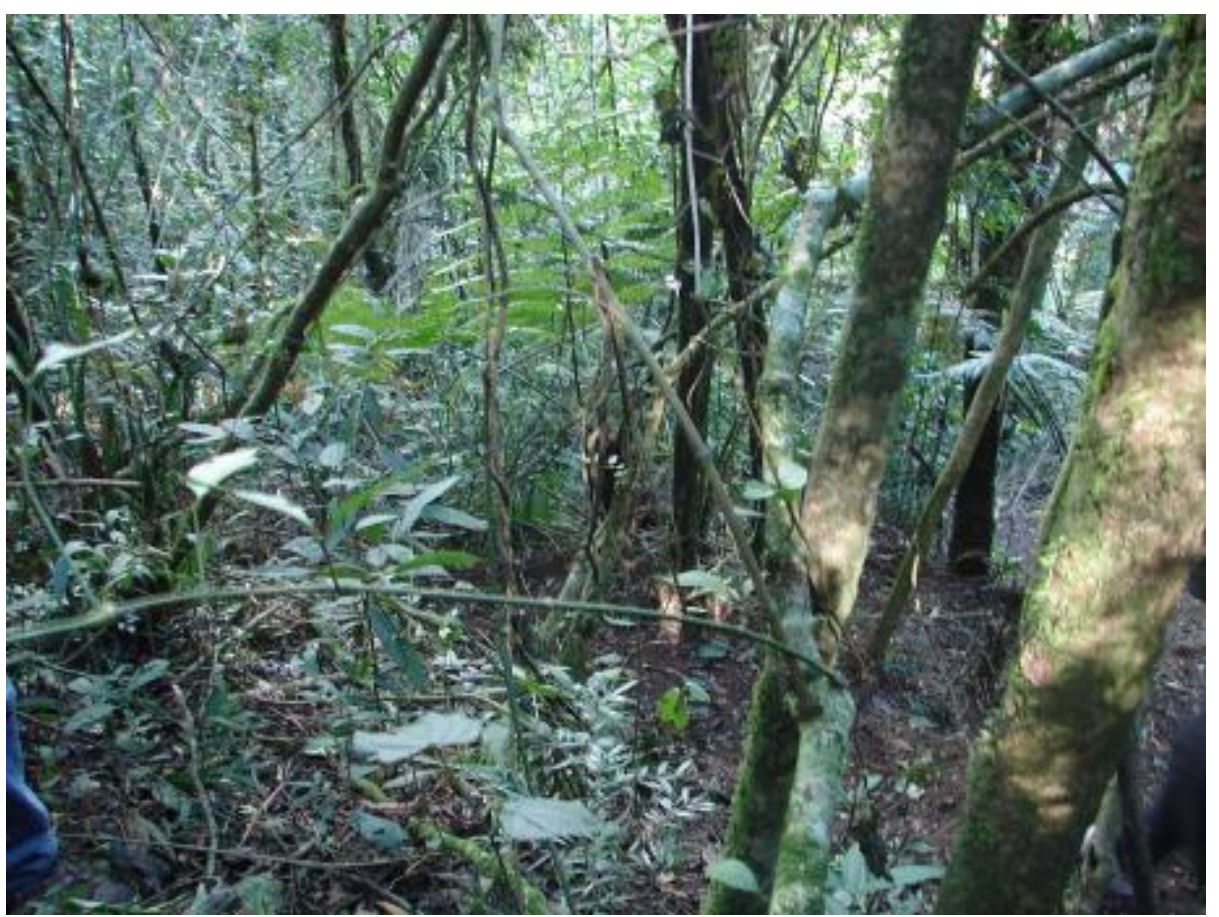

Figura 4: Área de mata nativa na Fazenda Mandaçaia, Camanducaia, MG Foto: Almerinda Fadini, maio/2011. 
Caminhadas interpretativas e conhecimento popular sobre plantas medicinais como forma de Educação Ambiental.

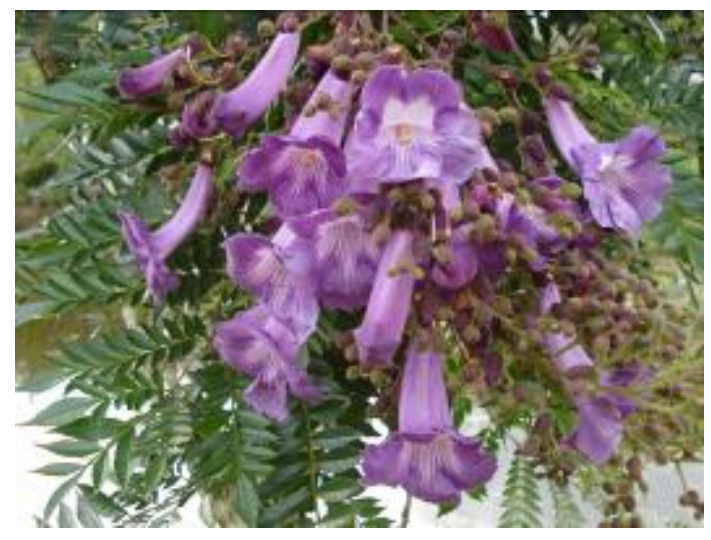

Figura. 5: Caroba (Jacaranda mimosaefolia) Foto: Thiago Comenale, dezembro/2011.

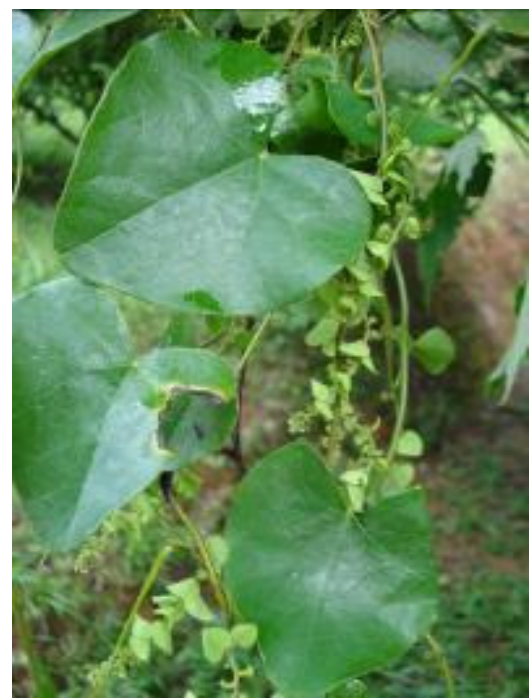

Figura 7: Buta (Cissampelos parreira)

Foto: Thiago Comenale, dezembro/2011.

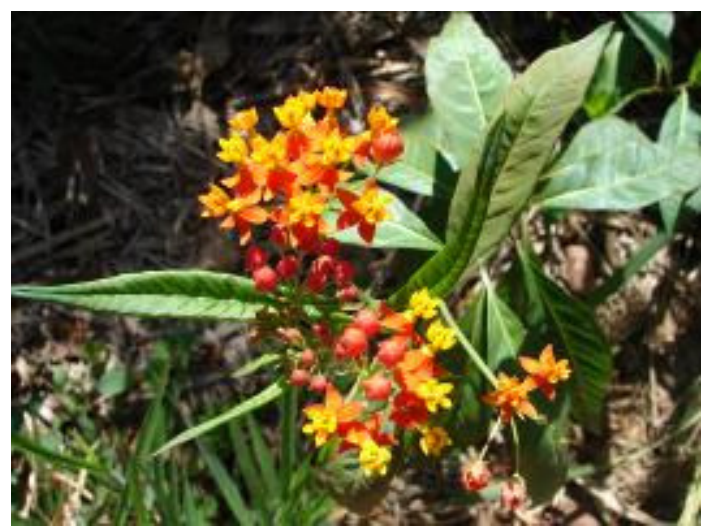

Figura 9: Oficial de sala (Asclepias curassavica L.) Foto: João Luiz Hoefel, março/2011.

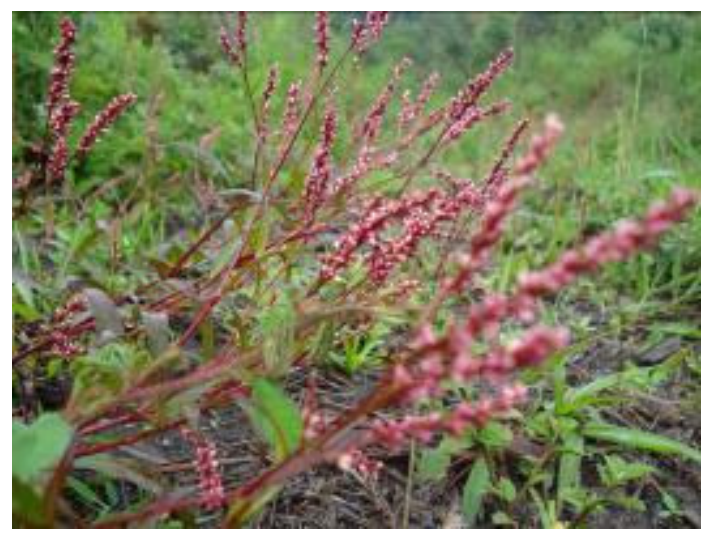

Figura 6: Erva-de-bicho (Polygonun persicaria) Foto: Thiago Comenale, dezembro/2011.

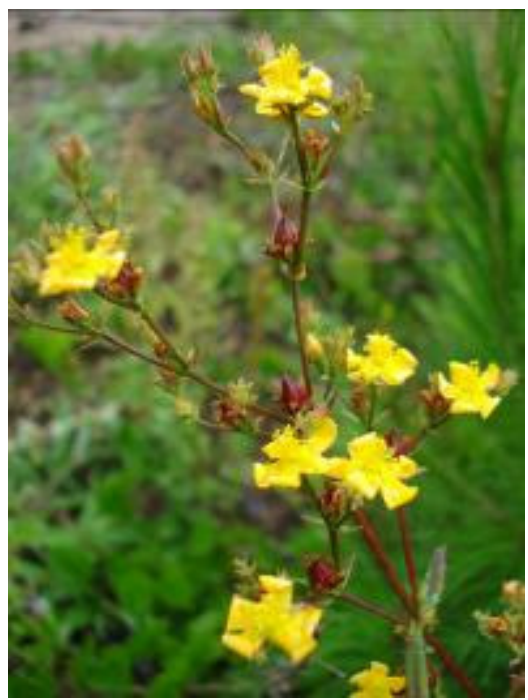

Figura 8: Erva-de-São-João (Hypericum brasiliense Choisy). Foto: Thiago Comenale, dezembro/2011.

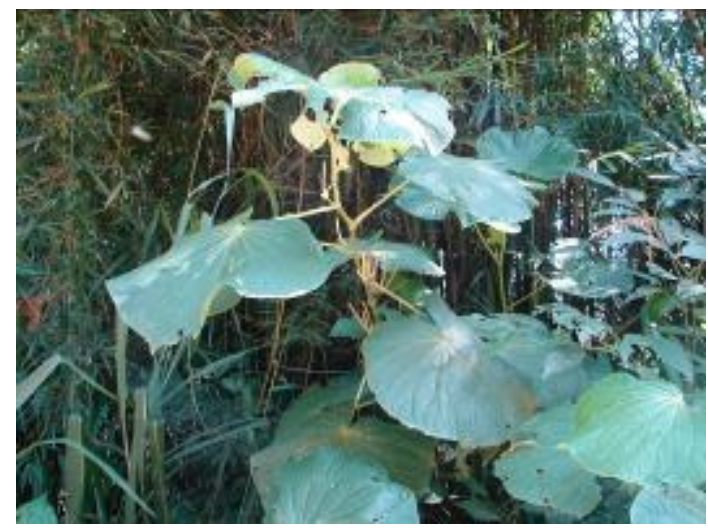

Figura 10: Pariparoba (Piper umbellatum) Foto: João Luiz Hoefel, março/2011. 
A diversidade de ambientes possibilita observar diferentes características das espécies de plantas medicinais. Na área antropizada encontra-se um tipo de vegetação, principalmente espécies arbustivas e rasteiras, distribuídas entre nativas e exóticas, muitas delas, em geral, consideradas como ervas daninhas.

Na maioria das vezes, estas plantas não são valorizadas, havendo uma supervalorização das espécies arbóreas (e nativas), devido à existência de uma percepção superficializada do ambiente.

Para a avaliação e identificação de eventuais adaptações necessárias, foi elaborado um questionário composto por 7 perguntas fechadas de múltipla escolha, com quatro opções de resposta (ótimo, bom, regular e péssimo) e 3 perguntas abertas com base na metodologia proposta por Richardson (1999) e Whyte (1978), aplicado ao término da atividade, com o intuito de avaliar características como a adequação do percurso e distância percorrida a públicos diferentes, a riqueza da biodiversidade local, a pertinência do tema proposto e o conhecimento adquirido sobre plantas medicinais. O questionário foi testado inicialmente com grupos compostos por alunos de cursos de graduação e de pós-graduação e turistas, totalizando 23 pessoas e a caminhada vem sendo realizada com público diverso que inclui moradores, alunos e professores de escolas da região e turistas.

De acordo com as respostas obtidas a maioria dos participantes considerou:

- Adequada a distância percorrida (ótima $44 \%$ e bom $48 \%$ ), considerando atender todas as faixas etárias, pelo fato do trajeto não ser muito acidentado e o percurso não ser muito longo;

- Ótima a pertinência da área geográfica escolhida (83\%) para o atendimento do objetivo principal (Educação Ambiental e conhecimento de plantas medicinais), uma vez que é possível identificar diversos aspectos socioambientais relevantes como, por exemplo, alterações antrópicas, áreas florestadas em excelente estado de regeneração, abundância de recursos hídricos, além de uma diversidade significativa de plantas medicinais;

- Ótima a satisfação com os conhecimentos adquiridos sobre plantas medicinais (87\%), devido ao fato do guia da caminhada possuir profundo conhecimento teórico e prático sobre a flora medicinal regional e conseguir apresentá-lo de uma forma atrativa;

- A diversidade e beleza dos atrativos naturais entre ótima (61\%) e boa (39\%), já que o percurso da caminhada encontra-se em uma área onde há adiantado estado de regeneração florestal, possui em seu entorno um relevo acidentado e diversos cursos de rios e quedas d'água;

- Ótima a possibilidade de interdisciplinaridade (65\%) proporcionada pela caminhada interpretativa, pois possibilita análises e reflexões sobre os efeitos das alterações antrópicas nos ambientes naturais e nas características socioculturais regionais;

- Ótima a riqueza da biodiversidade local (57\%), caracterizada por uma ampla diversidade de plantas medicinais e, conforme mencionado anteriormente, nesta região 
Caminhadas interpretativas e conhecimento popular sobre plantas medicinais como forma de Educação Ambiental.

foram identificadas 138 espécies, das quais 76 são nativas, 56 exóticas e 06 não puderam ser identificadas;

- Ótimo o processo de aprendizagem proporcionado pela metodologia de caminhadas interpretativas (74\%), uma vez que a mesma permite através da educação ao ar livre, integrar questões teóricas com exemplos concretos identificados e analisados durante o trajeto.

Os resultados obtidos com as aplicações dos questionários sobre a caminhada indicam que seus diferentes aspectos foram bem avaliados e que esta estratégia pode auxiliar na manutenção de um conhecimento tradicional e na valorização e conservação da biodiversidade. Através de uma divulgação mais ampla desta atividade, realizada inclusive pelos participantes, verificou-se o interesse da comunidade e de turistas na sua continuidade e ampliação.

Desta forma, a realização das caminhadas interpretativas pode ilustrar a forma como os moradores locais se relacionam com o meio ambiente e com as plantas medicinais regionais e mostra-se interessante, pois além de enfocar especificamente este tema, pode possibilitar a conservação ambiental através de uma atividade turística, que promoverá a valorização de um conhecimento difundido nas comunidades rurais, mas que, devido às transformações socioambientais, está se perdendo (Figura 11).

Verifica-se que a interpretação ambiental é uma oportunidade de difundir os valores e costumes dos lugares e comunidades visitadas, os quais, sem esta atividade, poderiam passar despercebidos.

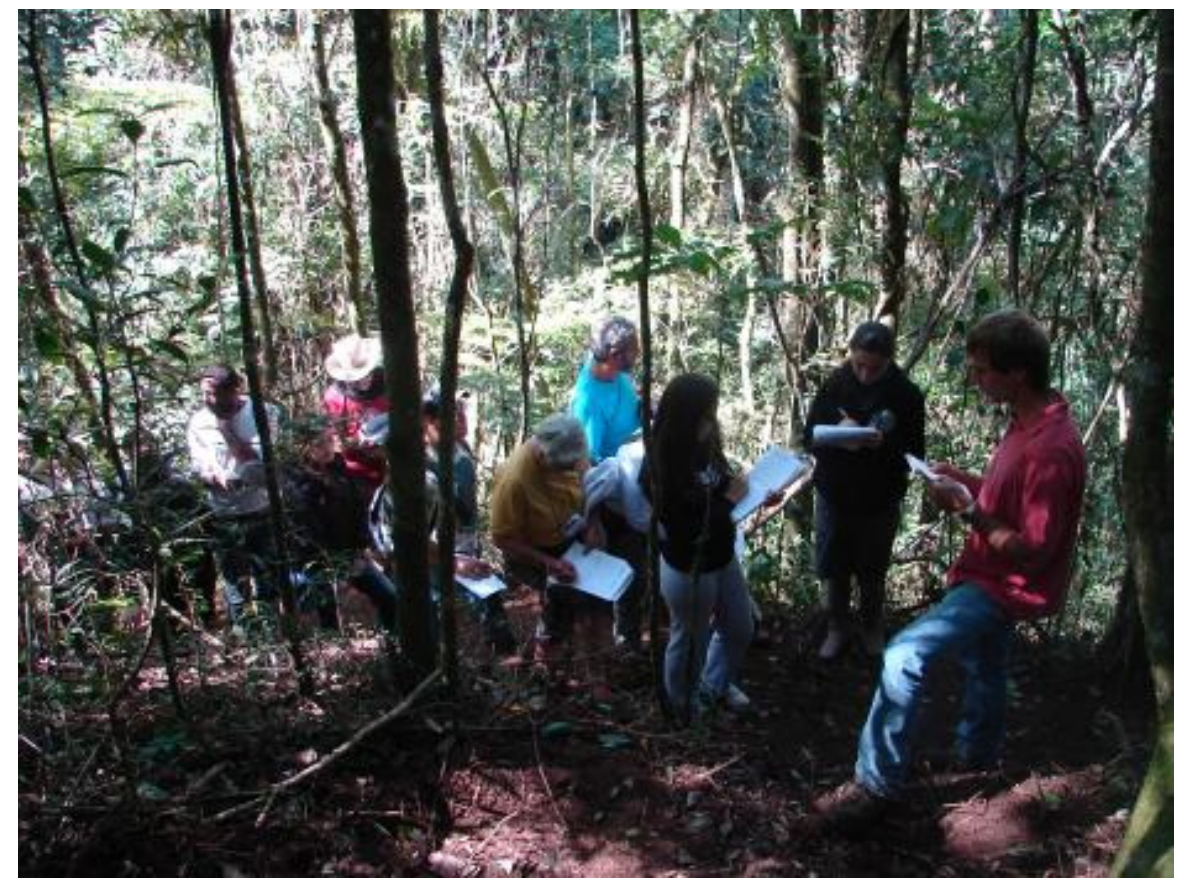

Figura 11: Caminhada interpretativa realizada na Fazenda Mandaçaia, Camanducaia, MG. Foto: Almerinda Fadini, maio/2011. 


\section{Algumas considerações}

A APA Fernão Dias é, sem dúvida, uma área de grande importância para a preservação do meio ambiente, e também de aspectos culturais da população local.

Verifica-se que esta localidade insere-se em uma realidade socioambiental que apresenta vulnerabilidades que geram diversos riscos. Esta situação demanda a elaboração de planejamento e ações integradas adequadas às características e especificidades desta área.

Os resultados obtidos neste trabalho demonstraram que se pode estimular a manutenção de práticas tradicionais relacionadas às plantas medicinais, já que estas configuram uma identidade ainda existente na localidade e em consonância com o meio ambiente em equilíbrio, através de atividades de educação e interpretação ambiental.

A Educação Ambiental corresponde a um importante instrumento para difundir o conhecimento e as práticas culturais populares e para estimular o desenvolvimento e envolvimento das comunidades em programas de uso sustentado dos recursos naturais.

A utilização de técnicas interpretativas contribui para a compreensão de fatos que estão além das aparências, assim, o desenvolvimento de caminhadas interpretativas no foco do conhecimento e uso popular de plantas medicinais podem auxiliar no entendimento da forma como as pessoas conhecem e se relacionam com as mesmas, possibilitando a manutenção dos recursos naturais através de uma atividade que promoverá a valorização de um conhecimento difundido nas comunidades rurais, mas que está se perdendo devido às transformações socioambientais.

Os dados obtidos até o momento com a realização desta caminhada interpretativa indicam que os participantes reconhecem o valor desta metodologia e percebem seu potencial como estratégia de Educação Ambiental e de enriquecimento pessoal.

Através da compreensão da realidade socioambiental desta APA é possível elaborar ações, planos e políticas socioeconômicas voltados para a preservação e conservação dos atributos naturais e culturais locais. Desta forma, a manutenção destes espaços torna-se imprescindível, porém isto só será possível através da adequação da forma de utilização deste espaço, bem como das atividades nele desenvolvidas, ao meio natural, de zoneamentos ambientais e de uso do solo, entre outras ações, que respeitem as suas dinâmicas e características.

\section{Referências Bibliográficas}

AZEVEDO, S.K.S.; SILVA, I.M. Plantas medicinais e de uso religioso comercializadas em mercados e feiras livres no Rio de Janeiro, RJ, Brasil. Acta bot. bras. v.20, n.1, p.185-194, 2006.

BEGOSSI, A.; HANAZAKI, N.; TAMASHIRO, J.Y. Medicinal plants in the Atlantic Forest (Brazil): knowledge, use and conservation. Human Ecology, New York, v. 30, n. 3, p. 281-299, 2002. 
Caminhadas interpretativas e conhecimento popular sobre plantas medicinais como forma de Educação Ambiental.

BARBOSA, S. R. C. S.; HOEFFEL, J. L.M. Qualidade de vida e complexidade social na APA Cantareira, SP: um estudo sobre degradação socioambiental e subjetividade. Relatório Parcial de Projeto de Pesquisa (FAPESP processo n. 06/60366-5), 2008.

BRASIL. Ministério da Industria, Comércio e Turismo / Ministério do Meio Ambiente (1994). Diretrizes para uma política nacional de ecoturismo. Brasília: Embratur / Ibama, 1994.

BRASIL. Lei n.o 9.985/2000 de 18 de julho de 2000 que institui o Sistema Nacional de Unidades de Conservação. Brasília: Imprensa Oficial, 2000.

BRASIL. Ministério do Turismo, Secretaria Nacional de Políticas de Turismo, Departamento de Estruturação, Articulação e Ordenamento Turístico. Ecoturismo: orientações básicas. Brasília: Ministério do Turismo, 2008.

BUTTEL, F.F. Sociologia ambiental, qualidade ambiental e qualidade de vida: algumas observações teóricas. In: HERCULANO, S.; PORTO, M.F.S. (Org.) Qualidade de vida \& riscos ambientais. Niterói: EDUFF, p. 29-48, 2000.

CUNHA, L.H. O. Saberes tradicionais pesqueiros. Desenvolvimento e Meio Ambiente, n.7 (jan/jun), p.71-79, 2003.

DIAS, R. Turismo, cidadania e Educação Ambiental. In: DIAS, R. Turismo sustentável e meio ambiente. São Paulo: Atlas, p. 159-181, 2003.

DRUMMOND, G. Biodiversidade em Minas Gerais: um atlas para sua conservação. Belo Horizonte: Fundação Biodiversitas, 2005.

FACO, R.A.; NEIMAN, Z. A natureza do ecoturismo: conceitos e segmentação. In: NEIMAN, Z.; RABINOVICCI, A. Turismo e meio ambiente no Brasil. Barueri, SP: Manole, p.43-62, 2010.

FENNELL, D.A. Ecoturismo e Ecoturistas. In: FENNELL, D.A. Ecoturismo. São Paulo: Contexto, p. 41-71, 2002. (Coleção Turismo Contexto)

GEERDINK, S.; NEIMAN, Z. A Educação Ambiental pelo turismo. In: NEIMAN, Z.; RABINOVICCI, A. Turismo e meio ambiente no Brasil. Barueri, SP: Manole, p.63-83, 2010.

GUIMARÃES, S.T.L. Nas trilhas das paisagens: heranças, recursos, valores. In: COSTA, N. M.C.; NEIMAN, Z.; COSTA, V.C. (Org.) Pelas trilhas do ecoturismo. São Carlos: RiMa, p. 53-72, 2008.

HOEFFEL, J. L.; GONÇALVES. N.M.; FADINI, A.A.B.; SEIXAS, S.R.C. Identidade, Saber Popular e Riscos Ambientais - Conhecimento e Uso de Plantas Medicinais nas Áreas de Proteção Ambiental do Sistema Cantareira (SP) e Fernão Dias (MG). Anais do XI Congresso Luso Afro Brasileiro de Ciências Sociais. Salvador: Universidade Federal da Bahia, p.1-15, 2011. Disponível em: http://www.xiconlab.eventos.dype.com.br/resources/anais/3/1314181584 ARQUIVO HOEFFEL,J.L.etal-IDENTIDADE,SABERPOPULARERISCOSAMBIENTAIS.pdf

HOEFFEL, J.L.; FADINI, A.A.B.; MACHADO, M.K. ; REIS, J.C.Trajetórias do Jaguary: Unidades de Conservação, Percepção Ambiental e Turismo - Um Estudo na APA do Sistema Cantareira, São Paulo. Ambiente \& Sociedade (Campinas), v. XI, p. 131-148, 2008.

HOEFFEL, J.L. FADINI, A.A.B. ; MACHADO, M.K. ; REIS, J.C. Trajetórias do Jaguary: a complexidade sócio-ambiental no Reservatório dos Rios Jaguary/Jacareí. Proceedings International Congress on Environmental Planning and Management. Brasília: Catholic University of Brasília, p. 1-16, 2005 (CD Rom). 
Hoefel, J.L.M.; Gonçalves, N.M.; Fadini, A.A.B.

HOEFFEL, J.L.; MACHADO, M.K. ; FADINI, A.; LIMA, F.B. Concepções e percepções da natureza na Área de Proteção Ambiental do Sistema Cantareira. Anais do IV Congresso Brasileiro de Unidades de Conservação. Curitiba: Fundação O Boticário, v.1, p.346-356, 2004.

HOEFFEL, J.L.; FADINI, A.A.B.; SEIXAS, S.R.C. Sustentabilidade, qualidade de vida e identidade local olhares sobre as APA's Cantareira/SP e Fernão Dias/MG. São Carlos: RiMa, 2010.

HOEFFEL, J. L.; GONÇALVES, N, M.; FADINI, A. A. B. Áreas de proteção ambiental Fernão Dias (MG) e do Sistema Cantareira (SP) - riscos socioambientais e aspectos relevantes para a conservação. OLAM, Rio Claro, SP. ano X, v.10, n. 2, , p. 90-124, Agosto-Dezembro/ 2010

LEFF, H. Complexidade Ambiental. São Paulo. Cortez, 2003.

LEWINGTON, A. Plants for people. London: The Natural History Museum, 1990.

LIMA, F.B. MACHADO, M. K. ; HOEFFEL, J. L. ; FADINI, A. A. B. Caminhada Interpretativa na natureza como instrumento para Educação Ambiental. Anais do II EPEA/UFSCar, 27 a 30 de julho de 2003 - São Carlos, 2003.

LUZZI, D. Educação Ambiental: pedagogia, política e sociedade. In: PHILIPPI-Jr., A.; PELICIONI, M.C.F. (editores). Educação Ambiental e sustentabilidade. Barueri: Manole, p. 381400, 2005.

MACIEL, M.A.P.M.; PINTO, A. C.; VEIGA, V. E. Plantas Medicinais: a Necessidade de Estudos Multidisciplinares. Quim. Nova, v.25 (3), P.429-438, 2002.

MARIOT, A.; REIS, M.S.; DI STASI, L.C. Fundamentos para o manejo de Piperáceas na Floresta Tropical Atlântica: demografia e fenologia reprodutiva. In: DIEGUES, A. C.; VIANA, V. M. (orgs.). Comunidades tradicionais e manejo dos recursos da Mata Atlântica. São Paulo: NUPAUB/LASTROP, pp. 57-64, 2000.

MINAS GERAIS. Decreto Estadual no 38.925, de 17 de Julho de 1997. Minas Gerais, Assembléia Legislativa, 1997.

NEIMAN, Z. Ecoturismo e Educação Ambiental em Unidades de Conservação: A importância da Experiência Dirigida. In: COSTA, N.M.C.; NEIMAN, Z.; COSTA, V.C. (org). Pelas Trilhas do Ecoturismo. São Carlos: RiMa, p. 33-49, 2008.

NEIMAN, Z.; RABINOVICI, A. Trilhas na natureza e sensibilização ambiental. In: COSTA, N. M.C.; NEIMAN, Z.; COSTA, V.C. (Org.) Pelas trilhas do ecoturismo. São Carlos: RiMa, p. 73-86, 2008.

OLIVEIRA, R. (Coord.) Plano de Gestão da Área de Proteção Ambiental Fernão Dias. Belo Horizonte: DER, 2007. 2v.

PAGANI, M.I.; SCHIAVETTI, A.; MORAES, M.E.B.; TOREZAN, F.E. As trilhas interpretativas da natureza e o ecoturismo. In: LEMOS, A. I. G. Turismo: Impactos Sócio-ambientais. São Paulo: Hucitec, São Paulo, p. 151-163. 1996.

PEREIRA, E.M. Interpretação: Valor adicional no turismo sustentável. In: NELSON, S.P.; PEREIRA, E.M.; Ecoturismo: Práticas para o turismo sustentável. Manaus: Vale / UniNorte, 2004.

PHILIPPI-Jr. A.; PELICIONI, M.C.F. Alguns Pressupostos da Educação Ambiental. In: PHILIPPI-Jr. A.; PELICIONI, M.C.F. (editores). Educação Ambiental: desenvolvimento de cursos e projetos. São Paulo: USP, Signus, p. 35, 2002. 
Caminhadas interpretativas e conhecimento popular sobre plantas medicinais como forma de Educação Ambiental.

RICHARDSON, R.J. Pesquisa Social. São Paulo: Atlas, 1999.

RODRIGUES, A.C.C.; GUEDES, M.L.S. Utilização de plantas medicinais no Povoado Sapucaia, Cruz das Almas - Bahia. Rev. Bras. PI. Med. Botucatu, v.8, n.2, p.1-7, 2006.

SANDERS. E. G. Ecoturismo e aspectos econômicos. In: NELSON, S. P.; PEREIRA, E. M. (Org.) Ecoturismo: Práticas para o turismo sustentável. Manaus: Editora Vale / UniNorte, p. 235-273, 2004.

SAUL, P.F.A.; LEAL, J.C P.; FENSTERSEIFER, C. Trilhas de Interpretação Ambiental. In: NOWATZKI, C.H. (Org.) Educação Ambiental: teoria e prática. São Leopoldo: Unisinos, p. 107-114, 2002.

SAUVÉ, L. Uma cartografia das correntes em Educação Ambiental. In: SATO, M.; CARVALHO, C. Educação Ambiental: Pesquisa e Desafios. Porto Alegre: ARTMED, 2005.

VASCONCELLOS, J. Trilhas interpretativas: aliando educação e recreação. Anais do Congresso Brasileiro de Unidades de Conservação, Curitiba, p.356-365, 1997.

VIEZZER, M.; OVALLES, O. (Org). Manual Latino americano de educ-ação ambiental. São Paulo: Gaia, 1994.

WHYTE, A. La perception de l'énvironnement: lignes directrices méthodologiques pour les études sur le terrain. Paris: UNESCO, 1978.

\section{Agradecimentos}

Trabalho elaborado com financiamento da Fundação de Amparo à Pesquisa do Estado de São Paulo - FAPESP, Projeto de Pesquisa $n^{\circ}$ 2008/10631-0 denominado: "Pharmácia do Mato - Transformações Socioambientais e Uso de Plantas Medicinais nas APA's Cantareira/SP e Fernão Dias/MG".

João Luiz de Moraes Hoefel: Universidade São Francisco, Bragança Paulista, SP, e Núcleo de Estudos em Sustentabilidade - Faculdades Atibaia, Atibaia, SP, Brasil.

Email: jlhoeffel@gmail.com

Link para o currículo Lattes: http://lattes.cnpq.br/7635072427530391

Nayra de Moraes Gonçalves: : Universidade São Francisco, Bragança Paulista, SP e Moinho D’Água Treinamentos, Nazaré Paulista, SP, Brasil.

Email: nayragoncalves@gmail.com

Link para o currículo Lattes: http://lattes.cnpq.br/9703941932203592

Almerinda Antonia Barbosa Fadini: Instituto Federal de São Paulo, Salto, SP, Brasil.

Email: almerindafadini@hotmail.com

Link para o currículo Lattes: http://lattes.cnpq.br/7835878522109146

Data de submissão: 29 de setembro de 2011

Data de recebimento de correções: 25 de janeiro de 2012

Data do aceite: 27 de janeiro de 2012

Avaliado anonimamente 